\title{
Congenital Hypothyroidism is Not Always Permanent: Caveats to Newborn Thyroid Screen Interpretation
}

\author{
ViJAYALAKSHMi BHATIA \\ Professor, Endocrinology,SGPGIMS, Lucknow226014.vbhatia@sgpgi.ac.in
}

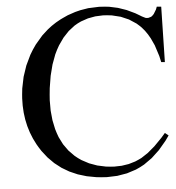

ongenital hypothyroidism $(\mathrm{CH})$ fulfills all the pre-requisites for being included in a newborn screening (NS) program. It does not present clinical features early and delayed diagnosis has disastrous consequences. Accurate biochemical diagnosis is possible before clinical features set in, and treatment by 2 to 3 weeks of age ensures good outcome. For India, two more important pre-requisites are fulfilled: $\mathrm{CH}$ is common (about 1 in 3000 infants) and its treatment is very easily affordable. Thyroid NS can be performed by measurement of TSH (commonly employed world wide) or T4 on cord blood or a neonatal sample at least 48 after birth. Like so many other initiatives in India, pediatricians and obstetricians have begun to recommend thyroid NS from their own health care facility, instead of waiting for the government to set up regional newborn screen programs. This has resulted in large numbers of timely diagnoses. It has also made it necessary for pediatricians to educate themselves on the caveats of thyroid NS.

A variety of physiological and pathological influences in the neonatal period pose difficulties in the interpretation of thyroid NS values. As per the joint guidelines of the American Academy of Pediatrics, American Thyroid Association and Lawson Wilkins Pediatric Endocrine Society, screening TSH $>40 \mathrm{mU} / \mathrm{L}$ should result in immediate recall of the baby and a confirmatory sample for $\mathrm{TSH}(1)$. If TSH is again $>40 \mathrm{mU} / \mathrm{L}$, treatment should commence after documenting a low $\mathrm{T} 4$ and an imaging (ultrasonography or radionuclide scan) of the thyroid. If the screen TSH is between 10 and 40 $\mathrm{mU} / \mathrm{L}$, a second screen is obtained in 2 weeks, to allow the hypothalamo-pituitary-thyroid (HPT) axis to mature. Mildly elevated TSH in many babies will eventually settle into the normal range. If that second TSH is also between 10 and $40 \mathrm{mU} / \mathrm{L}$, one may opt to follow up for another 2 weeks or to treat. If treatment is given, it is interrupted after 3 years for 1 month, to reevaluate for permanence of $\mathrm{CH}$. If TSH and $\mathrm{T} 4$ are now normal, the diagnosis would be transient $\mathrm{CH}$. Ten percent of permanent $\mathrm{CH}$ would have had screen $\mathrm{TSH}$ between 10 and $40 \mathrm{mU} / \mathrm{L}$.

In their study in this issue of the journal, Nair, et al. report on re-evaluation of the thyroid axis in 36 toddlers, now aged 3 years, diagnosed to have $\mathrm{CH}$ during infancy(2). The diagnosis of $\mathrm{CH}$ was based on initial TSH $>20 \mathrm{mU} / \mathrm{L}$ in babies $<2$ weeks of age, and $\mathrm{TSH}>10 \mathrm{mU} / \mathrm{L}$ in babies $>2$ weeks of age. Fifty percent had normal TSH off medication at 3 years. This study gives valuable information as it highlights that in this pool of patients - at least $50 \%$ would have had lifelong therapy unnecessarily had they not been re-evaluated.

What diagnostic category would these children belong to? Etiologies, as mentioned by the authors in their introduction, include iodine deficiency, iodine exposure of skin, maternal Graves disease or its treatment, and transplacental passage of maternal TSH receptor blocking antibodies (different from the common peroxidase antibodies of Hashimoto thyroiditis). These are rare conditions. True transient hypothyroidism is characterized by low $\mathrm{T} 4$ and typically a moderately high TSH in the neonatal period, which then are documented to be normal at 3 years of age. However, as seen in the study by 
Eugster et al, even babies with screen TSH as high as 77,210 and $>500 \mathrm{mU} / \mathrm{L}$ eventually were proven to have transient $\mathrm{CH}(3)$. Sometimes, the finding of high T4 during therapy may prompt re-evaluation even earlier than 3 years(4).

Let us examine the other causes of TSH between 10 and $40 \mathrm{mU} / \mathrm{L}$ in a newborn, especially with normal T4. The most common are (a) early sampling, before the TSH surge has subsided; and (b) delayed maturation of the HPT axis. These are often sorted out on the 2 week repeat screen. In the absence of more details, it is possible that some of the babies in Nair's study may have belonged to this category. Other important causes of difficult-tointerpret neonatal thyroid functions have a low T4, normal TSH picture. These may be due to prematurity, sick euthyroidism in a critically ill term or preterm newborn or rarely, central hypothyroidism originating from pituitary-hypothalamus. Many screening programs routinely perform a repeat screen after 2 weeks in all preterm infants.

The role of imaging in thyroid NS is crucial. Ultrasonography or radionuclide imaging showing athyreosis, hemithyroid, ectopic or goitrous glands give clues to the permanence of $\mathrm{CH}$. Having said that, it must be pointed out that transient $\mathrm{CH}$ conditions such as transfer of maternal TSH receptor blocking antibodies and iodine induced hypothyroidism may resemble athyreosis on a radionuclide scan and iodine deficiency may produce a goiter resembling dyshormonogenesis(3). Thus, ultrasonography and radionuclide imaging may be complementary to each other.
In summary, not all babies diagnosed to have $\mathrm{CH}$ in the newborn period will have permanent $\mathrm{CH}$. Avoiding early sampling (or being aware of age related norms or opting for cord blood sampling), doing a follow up screen for mildly elevated TSH values, using imaging modalities before start of therapy, and re-evaluation at 3 years of age for those infants who did not have a sound documentation of permanence, are useful strategies to avoid lifelong unnecessary therapy.

Funding: None.

Competing interests: None stated.

\section{REFERENCES}

1. American Academy of Pediatrics, Rose SR; Section on Endocrinology and Committee on Genetics, American Thyroid Association, Brown RS, Public Health Committee, Lawson Wilkins Pediatric Endocrine Society, Foley T, Kaplowitz PB, Kaye CI, Sundararajan S, Varma SK. Update on newborn screening and therapy for congenital hypothyroidism. Pediatrics 2006; 117: 2290-2303.

2. Nair PS, Sobhakumar S, Kailas L. Diagnostic reevaluation of children with congenital hypothyroidism. Indian Pediatr 2010; 47: 757-760.

3. Eugster EA, LeMay D, Zerin JM, Pescovitz OH. Definitive diagnosis in children with congenital hypothyroidism. J Pediatr 2004; 144: 643-647.

4. Zung A, Tenenbaum-Rakover $\mathrm{Y}$, Barkan S, Hanukoglu A, Hershkovitz E, Pinhas-Hamiel O, et al. Neonatal hyperthyrotropinemia: population characteristics, diagnosis, management and outcome after cessation of therapy. Clin Endocrinol (Oxf) 2010; 72: 264-271. 